\title{
Freehand S2 Alar-lliac Screw Placement Using K-Wire and Cannulated Screw : Technical Case Series
}

\author{
Ho Yong Choi, M.D., ${ }^{1}$ Seung-Jae Hyun, M.D., Ph.D., ${ }^{2}$ Ki-Jeong Kim, M.D., Ph.D., ${ }^{2}$ Tae-Ahn Jahng, M.D., Ph.D., ${ }^{2}$ \\ Hyun-Jib Kim, M.D., Ph.D. ${ }^{2}$ \\ Department of Neurosurgery, Samsung Changwon Hospital, Sungkyunkwan University School of Medicine, Changwon, Korea \\ Department of Neurosurgery, ${ }^{2}$ Spine Center, Seoul National University Bundang Hospital, Seoul National University College of Medicine, \\ Seongnam, Korea
}

Objective : Among the various sacropelvic fixation methods, S2 alar-iliac (S2Al) screw fixation has several advantages compared to conventional iliac wing screw. However, the placement of S2AI screw still remains a challenge. The purpose of this study was to describe a novel technique of free hand S2Al screw insertion using a K-wire and cannulated screw, and to evaluate the accuracy of the technique.

Methods : S2Al screw was inserted by free hand technique in sixteen consecutive patients without any fluoroscopic guidance. The gearshift was advanced to make a pilot hole passing through the sacroiliac joint and directing the anterior inferior iliac spine. A K-wire was placed through the pilot hole. After introducing a cannulated tapper along with the K-wire, a cannulated S2Al screw was installed over the K-wire.

Results : Thirty-three S2AI screws were placed in sixteen consecutive patients. Thirty-two screws were cannulated screws, and one screw was a conventional non-cannulated screw. Thirty out of 32 (93.8\%) cannulated screws were accurately positioned, whereas two cannulated screws and one non-cannulated screw violated lateral cortex of the ilium.

Conclusion : The technique using K-wire and cannulated screw can provide accurate placement of free hand S2AI screw.

Key Words : S2 alar-iliac screw · Sacropelvic fixation · Free hand technique · Cannulated screw.

\section{INTRODUCTION}

In long-level fusion surgery that extends to the sacrum, fixation failure and pseudarthrosis in the lumbosacral junction continue to be a challenge for spine surgeons ${ }^{7}$. A $24 \%$ rate of pseudarthrosis at the lumbosacral junction in adult scoliosis surgery was reported, ant it has been shown to be associated with adverse clinical outcomes ${ }^{8}$. These adverse outcomes could be attributed to poor bone quality of the sacrum, complex regional anatomy, and the substantial biomechanical forces ${ }^{1,3)}$.

To address these issues, various techniques of sacropelvic fixation including trans-iliac bars, iliac wing screws, and iliosacral screws have been proposed. Among these, Galveston

- Received : December 29, 2016 •Revised : March 23, 2017 •Accepted : April 11, 2017

- Address for reprints : Seung-Jae Hyun, M.D., Ph.D.

Department of Neurosurgery, Spine Center, Seoul National University Bundang Hospital, Seoul National University College of Medicine, 82 Gumi-ro 173beon-gil, Bundang-gu, Seongnam 13620, Korea

Tel : +82-31-787-7164, Fax : +82-31-787-4059, E-mail : hyunsj@snu.ac.kr

This is an Open Access article distributed under the terms of the Creative Commons Attribution Non-Commercial License (http://creativecommons.org/licenses/by-nc/4.0) which permits unrestricted non-commercial use, distribution, and reproduction in any medium, provided the original work is properly cited. 
method and iliac wing screw fixation techniques have most commonly been used, with high fusion rates ${ }^{2}$. Compared to Galveston technique, iliac wing screw technique is technically less demanding, and the pull-out strength of the iliac wing screw is three times that of the Galveston $\operatorname{rod}^{10,16}$. However, there are several concerns regarding the conventional iliac wing screw technique, which have such as increased risk of infection owing to wide dissection of soft tissue, implant prominence, and painful hardware ${ }^{2,3,18)}$.

S2 alar-iliac (S2AI) screws, an alternative for the traditional iliac wing screws, have recently been introduced and have become popular. Several studies have reported successful results with the S2AI screws in adult and pediatric populations ${ }^{13,17,19)}$. The major advantages of S2AI screws over traditional iliac wing screws are that they have a lower profile, they are in line with the cephalad instrumentation without the need for offset connectors, and they do not require a separate fascial inci$\operatorname{sion}^{2,14,17)}$. Further, previous researchers have demonstrated that S2AI screws can be inserted by free-hand technique or by percutaneous methods ${ }^{12,15)}$.

However, we experienced several cortical violations due to misplacement of the screw from the original pilot hole, which we had confirmed as intraosseous. To address this issue, we developed a novel S2AI screw insertion technique using a Kwire and cannulated screw, which could ensure accurate placement of S2AI screw.

\section{MATERIALS AND METHODS}

\section{Study design and patients}

This was a single-center, retrospective case series involving adult patients with spinal deformity who required sacropelvic fixation as part of a long-level thoraco-lumbar fusion.

\section{Surgical procedure}

S2AI screw placement was performed by free hand technique, using anatomical landmarks of the dorsal aspect of the sacrum. The starting point of the S2AI screw was located at the midpoint between the lateral aspect of the S1 and S2 foramina and $2 \mathrm{~mm}$ medial to the lateral sacral crest. After flipping a patient to the prone position on the operating table, a portable lateral plain radiograph was acquired and imaginary lines were drawn for the ideal pedicle screw trajectory and S2AI screw trajectory. A 3-mm cutting burr was used to create a posterior cortical breach, approximately $5 \mathrm{~mm}$ in depth. The gearshift was advanced to make a pilot hole passing through the sacroiliac joint and directing the anterior inferior iliac spine, as previously described ${ }^{15}$. The pilot hole could be verified by a ball-tip sounder to palpate the five bony borders (medial, lateral, superior, inferior, and bottom).

A K-wire was then inserted through the pilot hole created by the gearshift. The screw length could be determined by using a ball-tip sounder on which the length was previously indicated. Subsequently, the pathway was tapped with a $6.5-\mathrm{mm}$ cannulated tap along with the K-wire. Finally, a cannulated screw was introduced over the guide wire into the pathway. Plain posterior anterior and lateral radiographs were taken to confirm the adequate placement of the screws (Fig. 1).

\section{RESULTS}

Sixteen patients (thirteen females and three males), with a mean age of $69.4 \pm 9.5$ years, underwent long level instrumented fusion surgery using S2AI cannulated screws. The preoperative diagnoses were degenerative flatback (nine patients), degenerative lumbar scoliosis (two patients), postoperative flatback (two patient), post-traumatic flatback (two patients),
(A)

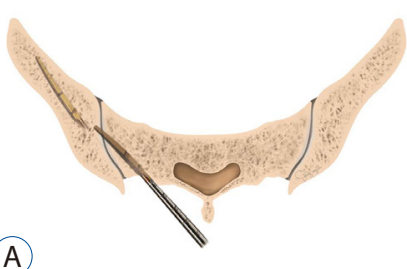

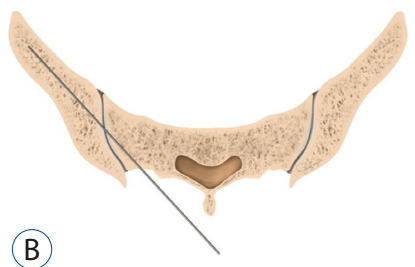
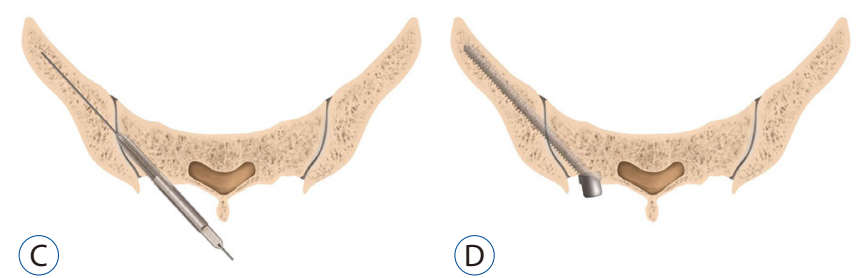

(D)

Fig. 1. A : The gearshift is initially pointed dorsally to avoid anterior wall violation of the pelvic bone. After crossing the sacroiliac joint, the tip is turned ventrally. B : After the pilot hole is created and verified as intraosseous, $\mathrm{K}$-wire is placed through the hole. C: Tapping is performed with a cannulated tap along with the K-wire. D : Cannulated S2 alar-iliac screw is inserted over the K-wire in the same manner. 
and pseudarthrosis (one patient). The mean number of fused levels was 8.8 (range, 4-16). The demographic data of the patients is summarized in Table 1.

A total of 33 S2AI screws were inserted in sixteen patients (Table 2). One of these was a conventional non-cannulated screw, which was inserted with the traditional iliac wing screw at the same side. The diameter of two screws was $7.5 \mathrm{~mm}$ and that of 31 screws was $8.5 \mathrm{~mm}$. The length of most screws was $80 \mathrm{~mm}$, except seven screws; three of $70 \mathrm{~mm}$, four of $90 \mathrm{~mm}$. The average caudal angle in the sagittal plane was $28.3 \pm 3.9^{\circ}$, while the average horizontal angle in the coronal plane was $40.2 \pm 3.8^{\circ}$.

Post-operative plain radiographs and computed tomography scans confirmed the screw placement. No violations of the cortical wall, sciatic notch, acetabulum, or pelvis were observed in 30 out of 32 (93.8\%) cannulated S2AI screws (Fig. 2). Among total of 33 S2AI screws, there was one conventional non-cannulated screw, in which a violation of the lateral cortex of the ilium was noted (Fig. 3).

\section{DISCUSSION}

S2AI screw fixation technique affords more stable biome- chanical durability against torsion force owing to the direction and length of the screws, resulting in more reliable stability compared to that provided by traditional iliac wing screw fixation $^{20)}$. Moreover, S2AI screw is technically easy to place because it requires minimal additional dissection, and is aligned in line without the need of the offset connector ${ }^{2,6)}$. Nevertheless, the placement of S2AI screw still remains a challenge for spine surgeons, and its misplacement may result in frequent cortical violations and serious neurovascular complications $^{7)}$. Therefore, we introduced a novel technique of S2AI screw placement using a K-wire and cannulated tapper and screw.

In the present case series, 30 S2AI screws out of 32 (93.8\%) were accurately placed in sixteen consecutive patients. Thus, using a K-wire and cannulated screw, S2AI screws could be inserted with acceptable success rate.

Cortical violation during screw placement can be minimized by careful use of gearshift probing ${ }^{9}$. Although the pilot hole violates the cortical wall, it can be identified using the ball-tip sounding device and salvaged thereafter ${ }^{11)}$. However, the pilot hole alone does not ensure that the screw will follow the pilot hole trajectory ${ }^{4}$, particularly in S2AI screwing as in case of patient 3 . We attribute the misplacement during tapping and screwing to failure to cross the sacroiliac joint ade-

Table 1. Patients demographic data

\begin{tabular}{|c|c|c|c|c|}
\hline Patient no. & Sex & Age & Diagnosis & Fused levels \\
\hline 1 & M & 64 & Degenerative lumbar scoliosis & T12 to pelvis \\
\hline 2 & M & 69 & Degenerative flatback & T8 to pelvis \\
\hline 3 & $\mathrm{~F}$ & 74 & Degenerative lumbar scoliosis & T3 to pelvis \\
\hline 4 & $F$ & 69 & Degenerative flatback & T10 to pelvis \\
\hline 5 & $\mathrm{~F}$ & 77 & Degenerative flatback & T10 to pelvis \\
\hline 6 & $F$ & 82 & Degenerative flatback & T9 to pelvis \\
\hline 7 & $\mathrm{~F}$ & 71 & Degenerative flatback & T10 to pelvis \\
\hline 8 & $\mathrm{~F}$ & 66 & Degenerative flatback & T10 to pelvis \\
\hline 9 & $F$ & 75 & Postoperative flatback & T10 to pelvis \\
\hline 10 & M & 75 & Pseudarthrosis & L3 to pelvis \\
\hline 11 & $\mathrm{~F}$ & 63 & Degenerative flatback & T10 to pelvis \\
\hline 12 & $\mathrm{~F}$ & 73 & Degenerative flatback & T11 to pelvis \\
\hline 13 & $\mathrm{~F}$ & 77 & Post-traumatic flatback & T10 to pelvis \\
\hline 14 & $F$ & 75 & Post-traumatic flatback & T10 to pelvis \\
\hline 15 & F & 42 & Postoperative flatback & L3 to pelvis \\
\hline 16 & $\mathrm{~F}$ & 58 & Degenerative flatback & T10 to pelvis \\
\hline
\end{tabular}

$M$ : male, $F$ : female 
Table 2. S2 alar-iliac (S2Al) screws profile, instrumentation angulation, and cortical violation

\begin{tabular}{|c|c|c|c|c|c|c|c|c|}
\hline \multirow{2}{*}{ Patient no. } & \multicolumn{2}{|c|}{ Diameter/length (mm) } & \multicolumn{2}{|c|}{ Caudal angle $\left({ }^{\circ}\right)$} & \multicolumn{2}{|c|}{ Horizontal angle $\left({ }^{\circ}\right)$} & \multicolumn{2}{|c|}{ Cortical violation } \\
\hline & Right & Left & Right & Left & Right & Left & Right & Left \\
\hline 1 & $7.5 / 80$ & $7.5 / 80$ & 28.2 & 29.2 & 39.2 & 43.0 & $N$ & $\mathrm{~N}$ \\
\hline 2 & $8.5 / 80$ & $8.5 / 70$ & 25.2 & 28.8 & 41.7 & 43.2 & $\mathrm{~N}$ & $\mathrm{~N}$ \\
\hline 3 & $8.5 / 80^{*}$ & $8.5 / 80$ & 18.6 & 18.3 & 38.1 & 39.0 & $Y^{*}$ & $N$ \\
\hline 4 & $8.5 / 80$ & $8.5 / 80$ & 27.0 & 31.1 & 34.6 & 34.9 & N & Y \\
\hline 5 & $8.5 / 80$ & $8.5 / 80$ & 23.5 & 24.2 & 37.2 & 39.5 & Y & $\mathrm{N}$ \\
\hline 6 & $8.5 / 70$ & $8.5 / 80$ & 32.4 & 31.4 & 44.4 & 46.4 & N & N \\
\hline 7 & $8.5 / 80$ & $8.5 / 80$ & 28.7 & 27.6 & 44.5 & 45.7 & N & N \\
\hline 8 & $8.5 / 90$ & $8.5 / 90$ & 28.1 & 28.8 & 35.7 & 37.6 & $\mathrm{~N}$ & N \\
\hline 9 & $8.5 / 80$ & $8.5 / 80$ & 30.7 & 30.4 & 41.4 & 39.7 & $N$ & $N$ \\
\hline 10 & $8.5 / 80$ & $8.5 / 80$ & 27.5 & 29.3 & 43.7 & 39.3 & $\mathrm{~N}$ & $\mathrm{~N}$ \\
\hline 11 & $8.5 / 80$ & $8.5 / 80$ & 32.7 & 36.4 & 42.1 & 46.7 & $\mathrm{~N}$ & $\mathrm{~N}$ \\
\hline 12 & $8.5 / 80$ & $8.5 / 90$ & 30.8 & 31.3 & 35.1 & 41.3 & $\mathrm{~N}$ & $N$ \\
\hline 13 & $8.5 / 80$ & $8.5 / 80$ & 26.9 & 29.3 & 42.0 & 46.2 & $N$ & $N$ \\
\hline 14 & $8.5 / 80$ & $8.5 / 80$ & 21.5 & 23.7 & 32.5 & 33.4 & $\mathrm{~N}$ & $\mathrm{~N}$ \\
\hline 15 & $8.5 / 80$ & $8.5 / 70$ & 30.8 & 32.9 & 38.9 & 38.2 & $\mathrm{~N}$ & $N$ \\
\hline \multirow[t]{2}{*}{$16^{\dagger}$} & $8.5 / 80$ & $8.5 / 90$ & 28.0 & 29.9 & 40.5 & 41.0 & $N$ & $N$ \\
\hline & $8.5 / 80$ & - & 29.5 & - & 40.0 & - & $\mathrm{N}$ & - \\
\hline
\end{tabular}

${ }^{*}$ Conventional non-cannulated S2AI screw. ${ }^{\dagger}$ Dual S2Al screw insertion at the right side. N : no, Y : yes
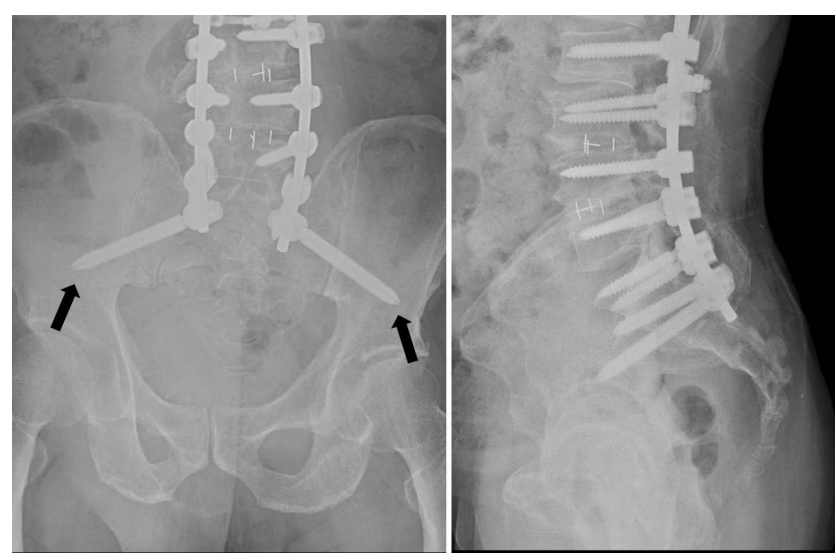

Fig. 2. Anteroposterior and lateral plain radiographs demonstrate $\mathrm{S} 2$ alar-iliac (S2AI) screw insertion using cannulated screws. Note the radiolucent line inside the screw (arrows). Two S2Al screws are accurately placed.

quately, poor bone quality of the sacrum with weak cancellous bone, and the narrow isthmus portion of the ilium. We recognized that most of the misplacement occurred during tapping through the pilot hole. Introduction of a cannulated tapper over a K-wire followed by a cannulated screw enabled us to accurately place the S2AI screw.

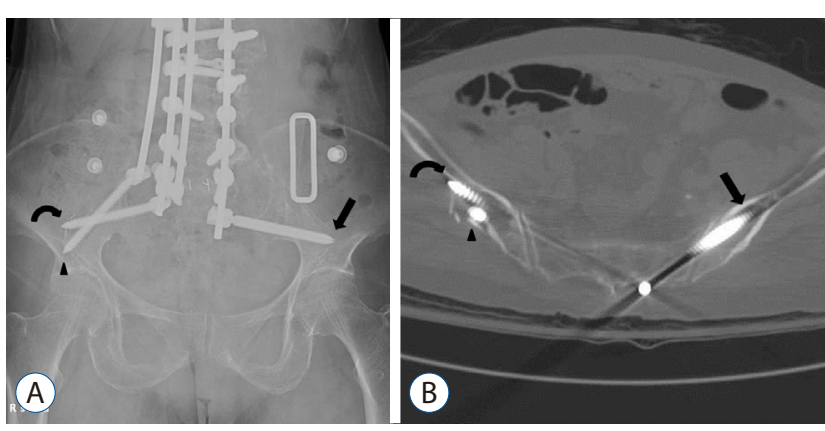

Fig. 3. A : Anteroposterior plain radiograph of Patient 3. A cannulated S2 alar-iliac (S2AI) screw (arrow) was inserted on the left side, whereas conventional non-cannulated S2Al screw (curved arrow) was inserted on the right side with the additional iliac wing screw (arrowhead). B : Computed tomographic axial image of the same patient demonstrates cortical violation of the lateral ilium by the conventional non-cannulated S2AI screw (curved arrow) and iliac wing screw (arrowhead). Cannulated S2Al screw (arrow) was accurately positioned on the left side.

Tapping is an essential procedure that ensures proper placement of pedicle screws ${ }^{9}$. Pedicle screw placement without tapping would result in screw malpositioning, even if the pilot hole was created accurately ${ }^{4}$. However, tapping itself through a long pilot hole also carries a risk of misplacement, which 
may trap the neurovascular structure by the sharp grooves of the tapping device. Use of a K-wire together with a cannulated tapper and screw could help reduce the risk of screw malpositioning and the resultant potential complications.

In most cases, S2AI screw placement is performed under intra-operative C-arm fluoroscopy. However, screw placement under fluoroscopic guidance requires more surgical time and carries a risk of radiation exposure for both surgeons and patients, despite the use of protective equipment and devices. Moreover, a recent study demonstrated that lead aprons were less protective than expected ${ }^{5}$. As previously reported in the cadaveric study $^{15}$, free hand insertion technique of S2AI screw could be an alternative method to address these concerns. Further, free hand S2AI screw insertion, using a K-wire, and cannulated tapper and screw may be useful for more accurate placement of the S2AI screw. Further studies with larger number of patients are warranted to verify the effectiveness and safety of this novel technique.

\section{CONCLUSION}

S2AI screw fixation has several advantages compared to conventional iliac wing screw. However, the placement of S2AI screw still remains a challenge. The technique using Kwire and cannulated screw can provide accurate placement of free hand S2AI screw as an alternative method.

\section{PATIENT CONSENT}

The patient provided written informed consent for the publication and the use of their images.

\section{- Acknowledgments}

We appreciate the assistance of Mijin Jung, the artist who drew Fig. 1 in this manuscript. She worked as a medical illustrator for the Department of Neurosurgery, Baylor College of Medicine from 2009 to 2011, and has worked in the Department of Neurosurgery, Seoul National University Bundang Hospital, Seoul National University College of Medicine from 2013 to 2015.

\section{References}

1. Balderston RA, Winter RB, Moe JH, Bradford DS, Lonstein JE : Fusion to the sacrum for nonparalytic scoliosis in the adult. Spine (Phila Pa 1976) $11: 824-829,1986$

2. Chang TL, Sponseller PD, Kebaish KM, Fishman EK : Low profile pelvic fixation: anatomic parameters for sacral alar-iliac fixation versus traditional iliac fixation. Spine (Phila Pa 1976) 34 : 436-440, 2009

3. Emami A, Deviren V, Berven S, Smith JA, Hu SS, Bradford DS : Outcome and complications of long fusions to the sacrum in adult spine deformity: luque-galveston, combined iliac and sacral screws, and sacral fixation. Spine (Phila Pa 1976) 27 : 776-786, 2002

4. Erkan S, Hsu B, Wu C, Mehbod AA, Perl J, Transfeldt EE : Alignment of pedicle screws with pilot holes: can tapping improve screw trajectory in thoracic spines? Eur Spine J 19 : 71-77, 2010

5. Hyun SJ, Kim KJ, Jahng TA, Kim HJ : Efficiency of lead aprons in blocking radiation - how protective are they? Heliyon 2 : e00117, 2016

6. Jain A, Hassanzadeh H, Strike SA, Menga EN, Sponseller PD, Kebaish $\mathrm{KM}$ : Pelvic fixation in adult and pediatric spine surgery: historical perspective, indications, and techniques: AAOS exhibit selection. J Bone Joint Surg Am 97 : 1521-1528, 2015

7. Kebaish KM : Sacropelvic fixation: techniques and complications. Spine (Phila Pa 1976) 35 : 2245-2251, 2010

8. Kim YJ, Bridwell KH, Lenke LG, Cho KJ, Edwards CC 2nd, Rinella AS Pseudarthrosis in adult spinal deformity following multisegmental instrumentation and arthrodesis. J Bone Joint Surg Am 88 : 721-728, 2006

9. Kim YJ, Lenke LG, Bridwell KH, Cho YS, Riew KD : Free hand pedicle screw placement in the thoracic spine: is it safe? Spine (Phila Pa 1976) 29 : 333-342; discussion 342, 2004

10. Kuklo TR, Bridwell KH, Lewis SJ, Baldus C, Blanke K, Iffrig TM, et al. : Minimum 2-year analysis of sacropelvic fixation and L5-S1 fusion using S1 and iliac screws. Spine (Phila Pa 1976) 26 : 1976-1983, 2001

11. Lehman RA, Potter BK, Kuklo TR, Chang AS, Polly DW, Shawen SB, et al. : Probing for thoracic pedicle screw tract violation(s): is it valid? J Spinal Disord Tech 17 : 277-283, 2004

12. Martin CT, Witham TF, Kebaish KM : Sacropelvic fixation: two case reports of a new percutaneous technique. Spine (Phila Pa 1976) 36 : E618-E621, 2011

13. Nottmeier EW, Pirris SM, Balseiro S, Fenton D : Three-dimensional image-guided placement of S2 alar screws to adjunct or salvage lumbosacral fixation. Spine J 10 : 595-601, 2010

14. O'Brien JR, Yu WD, Bhatnagar R, Sponseller P, Kebaish KM : An anatomic study of the $\mathrm{S} 2$ iliac technique for lumbopelvic screw placement. Spine (Phila Pa 1976) 34 : E439-E442, 2009

15. Park JH, Hyun SJ, Kim KJ, Jahng TA : Free hand insertion technique of S2 sacral alar-iliac screws for spino-pelvic fixation: technical note, acadaveric study. J Korean Neurosurg Soc 58 : 578-581, 2015

16. Schwend RM, Sluyters R, Najdzionek J : The pylon concept of pelvic anchorage for spinal instrumentation in the human cadaver. Spine (Phila Pa 1976) 28 : 542-547, 2003 
17. Sponseller PD, Zimmerman RM, Ko PS, Pull Ter Gunne AF, Mohamed AS, Chang TL, et al. : Low profile pelvic fixation with the sacral alar iliac technique in the pediatric population improves results at two-year minimum follow-up. Spine (Phila Pa 1976) 35 : 1887-1892, 2010

18. Tsuchiya K, Bridwell KH, Kuklo TR, Lenke LG, Baldus C : Minimum 5-year analysis of L5-S1 fusion using sacropelvic fixation (bilateral S1 and iliac screws) for spinal deformity. Spine (Phila Pa 1976) 31 : 303-308,
2006

19. Wind JJ, Burke LM, Kurtom KH, Roberti F, O'Brien JR : Minimally invasive lumbopelvic instrumentation for traumatic sacrolisthesis in an elderly patient. Eur Spine J 21 Suppl 4 : S549-S553, 2012

20. Zhu F, Bao HD, Yuan S, Wang B, Qiao J, Zhu ZZ, et al. : Posterior second sacral alar iliac screw insertion: anatomic study in a Chinese population. Eur Spine J 22 : 1683-1689, 2013 